\title{
Rolipram as a Discriminative Stimuli: Transfer to Phosphodiesterase Inhibitors
}

\author{
Tsuneyuki YAMAMOTO, Kazuyo MIYAMOTO and Showa UEKI \\ Department of Pharmacology. Faculty of Pharmaceutical Sciences. \\ Kyushu University 62. Fukuoka 812. Japan \\ Accepted October 24. 1986
}

\begin{abstract}
Rats were trained to discriminate ( $t)$-rolipram $(0.32 \mathrm{mg} / \mathrm{kg}$, i.p.) from saline in a two-lever food-reinforced drug discrimination procedure (FR 10). ( \pm )Rolipram served as a drug discriminative stimulus, and its discrimination was readily established with a mean of 42 training sessions to achieve criterion performance (at least $80 \%$ correct response in the consecutive generalization tests with both saline and $( \pm)$-rolipram). Thereafter, this stimulus was stably maintained. The $(-)$-isomer of rolipram was generalized at about one-third of the training dose of the ( \pm -compound, but the $(+)$-isomer was generalized only at 10 times the dose of the $( \pm)$-compound. This finding suggests that the $(-)$-compound is more extensively involved as a stimulus than either $( \pm)$-rolipram or the $(+)$-isomer. Ro20-1724, caffeine and theophylline, which are phosphodiesterase inhibitors, were generalized to $( \pm)$-rolipram. This result strongly suggests that phosphodiesterase inhibition may be an important factor involved in ( \pm )-rolipram discrimination.
\end{abstract}

Drug discrimination learning using drugs as discriminative stimuli is considered to reflect the substitution effect of drugs. Recently, drug discrimination has been frequently utilized as a unique behavioral method for the classification of drugs (1) and for the preclinical evaluation of subjective effects of drugs in man $(2,3)$. Psychoactive drugs generally have discriminative properties (4), but drug discriminative learning is said to be comparatively difficult with antidepressants as they produce less effective discriminative stimuli (5).

( \pm - Rolipram [4-(3-cyclopentyloxy-4methoxyphenyl)-2-pyrrolidone] is a dialkoxyphenyl pyrrolidone derivative which a) antagonizes reserpine-induced hypothermia and hypoactivity (6). b) significantly decreases the immobility time in a forced swimming test ( 7 ), and c) potentiates yohimbine toxicity (6). In view of these actions, this compound has been regarded as a new antidepressant (8). Biochemical studies have shown that, like atypical antidepressants, rolipram has no anti-cholinergic effect and inhibits neither monoamine oxydase nor monoamine re-uptake $(6,9)$. On the other hand, it significantly inhibits cerebral phosphodiesterase $(10,11)$.

The present study was designed to ascertain whether $( \pm)$-rolipram would serve as a discriminative stimulus in drug discrimination learning and, provided that drug discrimination learning could be established. to clarify the discriminative characteristics of ( \pm )-rolipram.

\section{Materials and Methods}

Animals: Ten male rats of the Slc: WistarKY strain (Shizuoka Laboratory Animals Center) were used. The rats were housed in groups of 4 per cage in a vivarium controlled at $21 \pm 2{ }^{\circ} \mathrm{C}$ and maintained at approximately $80 \%$ of free-feeding weight throughout the experimental period. Each rat was given $10 \mathrm{~g}$ laboratory food pellets after completion of each daily session. Water was available ad lib.

Drugs: The following drugs were used: $( \pm)$-rolipram and its (+)-isomer and (-)- 
isomer (Schering AG., Berlin), Ro20-1724 [4-(3-n-butoxy-4-methoxybenzyl)-2-imidazolidinone] (Hoffmann-La Roche), anhydrous theophylline (Sigma Chemical Co.), and anhydrous caffeine (Yoneyama Yakuhin Kogyo Co., Ltd.)

All drugs were suspended in 1\% methylcellulose $(\mathrm{MC})$ and administered i.p. in a constant volume of $1 \mathrm{ml} / \mathrm{kg}$.

Apparatus: The Skinner box equipped with two levers was used. The levers were disposed $17 \mathrm{~cm}$ apart at a height of $5.5 \mathrm{~cm}$ above the floor grid, with a feeder being mounted between the levers.

Procedure: Each rat was first trained to learn how to obtain one food pellet (about $50 \mathrm{mg}$. Muromachi Kikai Co., Ltd.) from the feeder as a positive reinforcement (Fixed Ratio 1: FR 1) by pressing either one of the two levers. After an establishment of the lever-pressing in FR 1 , the ratio was gradually increased until FR 10. After the establishment of the FR10 lever-pressing condition, drug discrimination training was initiated.

Each rat was immediately put into the Skinner box. ( \pm )-Rolipram or saline were injected i.p. $30 \mathrm{~min}$ prior to the training sessions. A possible effect of lever preference was counter-balanced by randomly assigning the right lever to be the drug lever for 5 rats and the left lever to be the drug lever for the other 5 rats. Discrimination training between $( \pm)$-rolipram $(0.32 \mathrm{mg} / \mathrm{kg})$ and saline was performed at FR 5 in sessions 1 to 11 and at FR 10 in session 12 and beyond. Discrimination training after alternative administration of saline or $( \pm)$-rolipram was conducted once a day, and each session ended when 50 reinforcements had been taken or after $30 \mathrm{~min}$. The experiment was performed six days per week. Generalization tests were conducted only in the rats that consistently responded with incorrect leverpressing of less than 15 in both ( \pm ) -rolipramand saline-training sessions.

For the generalization test, the rat was put in the Skinner box immediately after i.p. administration of the drug and the test was started $30 \mathrm{~min}$ later. In the generalization test schedule, the rat was able to obtain food by responding 10 times on either of the two levers. The generalization test was also terminated when the rat had obtained the 50 th reinforcement or at the end of a test time of $30 \mathrm{~min}$.

\section{Results}

1. The acquisition curve for $( \pm)$-rolipram: The FR 10 response was established after about 10 training sessions.

The upper part of Fig. 1 shows the acquisition curve for $( \pm)$-rolipram discrimination. Trained rats achieved at least $80 \%$ correct response in the consecutive generalization tests with both saline and $( \pm)$ rolipram after 33 sessions at the earliest and 55 sessions at the latest. The discriminative learning was established after a mean of 42 sessions and was well maintained thereafter. The lower part of Fig. 1 shows the changes in response rate during discrimination training. Throughout the training period, the response rate in the $( \pm)$-rolipram-session was about $27 \%$ less than the rate in the saline session.

After completion of discriminative learning, generalization tests using various doses of $( \pm)$-rolipram were performed $(N=10)$. The $( \pm)$-rolipram-appropriate response was expressed as the total number of responses shown by each rat until it took the 50th pellet or until a test time of $30 \mathrm{~min}$ had expired. The appropriate response to $( \pm)$ rolipram was found to increase in a dosedependent manner (Figs. 2 and 3 ). Thus the $( \pm)$-rolipram-appropriate response was $0.7 \%$ for the vehicle alone, $23.8 \%$ at 0.032 $\mathrm{mg} / \mathrm{kg}, 58.7 \%$ at $0.1 \mathrm{mg} / \mathrm{kg}$, and $98.9 \%$ at the training dose of $0.32 \mathrm{mg} / \mathrm{kg}$ (Fig. 3 ). On the other hand, the response rate was found to decline in a dose-dependent manner (Fig. 3).

2. Generalization tests with the optical isomers of rolipram: The results of generalization tests with the optical isomers of rolipram are shown in Fig. 3. Both the $(+)$ rolipram $(N=6)$ and $(-)$-rolipram $(N=6)$ showed the $( \pm)$-rolipram-appropriate response in a dose-dependent manner, but there was a difference in the dose required. Namely, (+)-rolipram at $3.2 \mathrm{mg} / \mathrm{kg}$ was generalized to the $( \pm)$-rolipram stimulus $(99.7 \%)$, whereas only $0.1 \mathrm{mg} / \mathrm{kg}$ of $(-)$ rolipram was required for generalization 

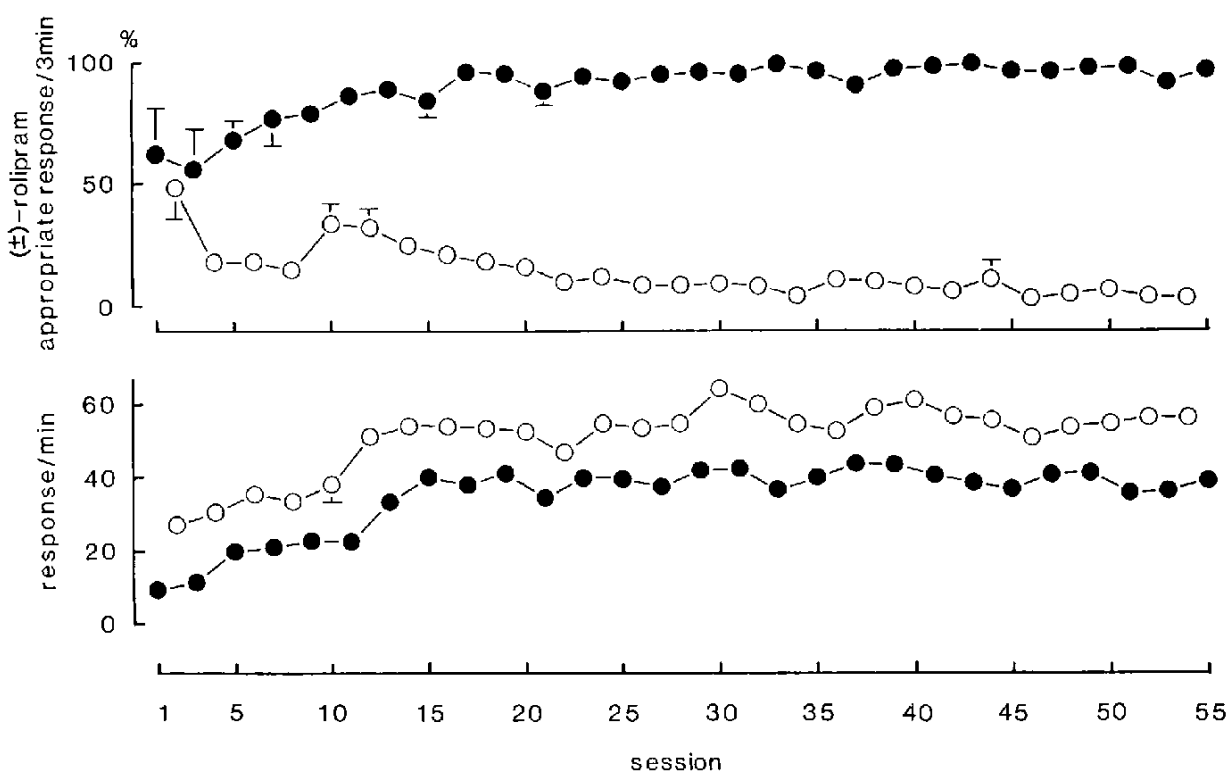

\section{- (t)-rolipram $\quad 0-0$ saline}

Fig. 1. Acquisition of a discrimination between ( \pm )-rolipram $0.32 \mathrm{mg} / \mathrm{kg}$ (i.p.) and saline in rats (upper panel: $N=10$ ). Values are the mean percent with S.E.M. of $( \pm$ )-rolipram for appropriate responding during $3 \mathrm{~min}$ following initiation of the test period. The response rate is expressed as the mean number of lever pressing responses per min (lower panel).

$(81.2 \%)$. On the other hand, both isomers slightly decreased the response rate (Fig. 3).

3. Generalization tests with phosphodiesterase inhibitors: Figure 4 shows results of generalization of phosphodiesterase inhibitors caffeine $(N=4)$, theophylline $(N=6)$ and Ro20-1724 $(N=5)$ to the $( \pm)$-rolipram stimulus. Rats treated with all three different phosphodiesterase inhibitors showed ( \pm )rolipram-appropriate responses in a dosedependent manner. The generalization doses were $3.2 \mathrm{mg} / \mathrm{kg}$ for Ro20-1724 and $56 \mathrm{mg} / \mathrm{kg}$ for caffeine and theophylline. Likewise, response rate was decreased by these phosphodiesterase inhibitors at these generalization doses.

\section{Discussion}

The present experiment showed that $( \pm)$ rolipram at a small dose $(0.32 \mathrm{mg} / \mathrm{kg})$ served as a discriminative cue and that its discrimination was stably maintained. Overtome and Batta (12) succeeded in training animals to discriminate doxepin, imipramine or amitryptyline from saline at relatively high doses in a shock-escape T-maze task. In a two-lever operant task, desipramine (10 $\mathrm{mg} / \mathrm{kg}$ ) has served as a discriminative stimulus (5). However, even in this case, only about one-half of the rats learned to discriminate. Furthermore, this dose produced an increase in mortality among the experimental subjects before extensive transfer testing could be accomplished (5). Jones et al. (13) reported that imipramine at $10 \mathrm{mg} /$ $\mathrm{kg}$ failed to be discriminated from saline in rats. From these findings, it has generally been considered that antidepressants produce drug discrimination with difficulty, and when discrimination is achieved, it can not be reliably maintained. In this respect, ( \pm )rolipram is qualitatively different from imipramine and desipramine.

Rolipram is a racemic drug which can be resolved into its optically active forms (+ and - ). In the present study, the (-)-isomer was generalized at a dose equal to about onethird of the training dose of the $( \pm)$ compound, but the $(+)$-isomer had to be used at a dose 10 times that of the $( \pm)$ - 

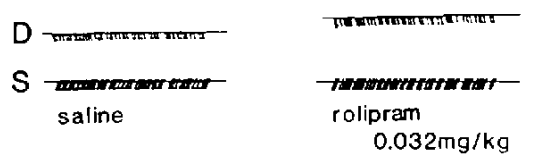

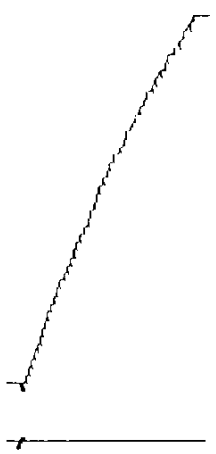

$0.1 \mathrm{mg} / \mathrm{kg}$

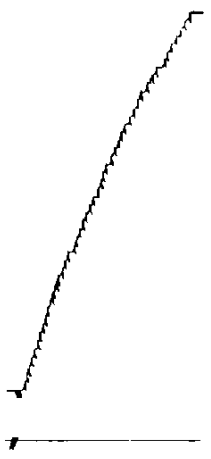

$0.32 \mathrm{mg} / \mathrm{kg}$ (i.p)
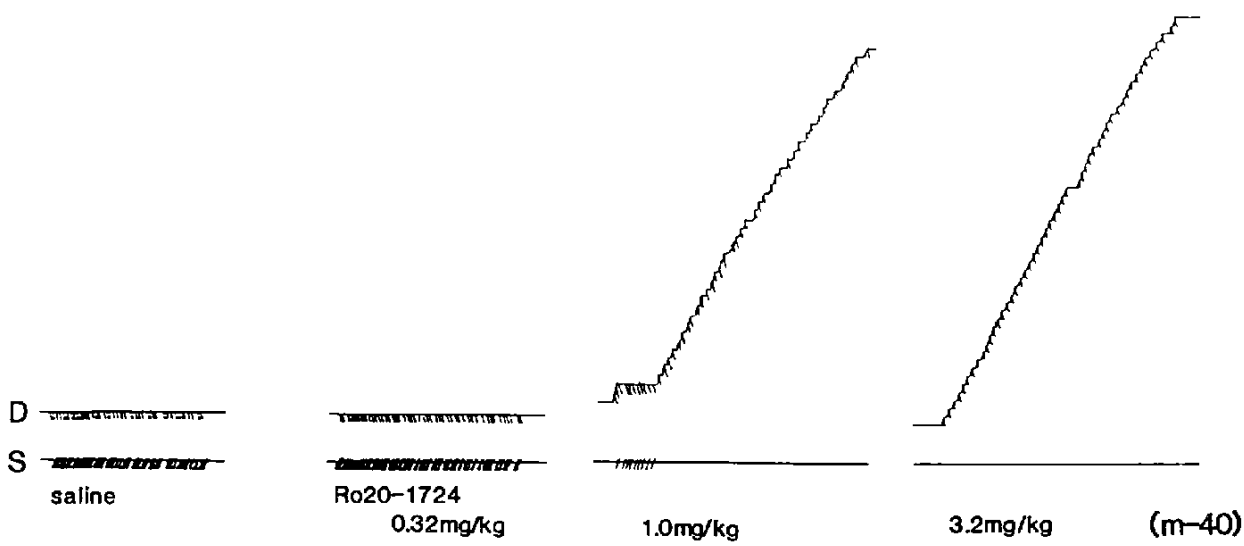

Fig. 2. Cumulative response records of performance under FR 10 after the administration of $( \pm)$-rolipram (upper panel) and Ro 20-1724 (lower panel) in ( \pm )-rolipram-trained rats. The response-marking pen (D) moves one step upward in turn with each ( \pm )-rolipram-appropriate response (pressing ( \pm )-rolipramlever). The event-marking pen ( $S$ ) indicates the saline appropriate response (pressing saline-lever). Positive reiniorcement (a $50 \mathrm{mg}$ food pellet) is indicated by a diagonal hash marked on the cumulative record.

compound to achieve the same effect. In the reserpine antagonism and yohimbine potentiation assays, the $( \pm)$-rolipram and its $(-)$ isomer showed approximately the same potency, but the $(+)$-compound was only $1 / 10$ to $1 / 15$ as potent as the $(-)$-compound (6.14). Present results of the generalization tests are substantially consistent with this finding. It is thus clear that the discriminative stimulus of rolipram is stereospecific and that the (-)-rolipram is more potent than the $(+)$-rolipram as a discriminative stimulus.

There are at least three types of phosphodiesterases: i) one is present in the membrane and hydrolyzes both cyclic AMP and cyclic GMP, but is insensitive to $\mathrm{Ca}^{++}$ and calmodulin (CaM); ii) the second is a low affinity enzyme $\left(\mathrm{K}_{\mathrm{m}}=300 \mu \mathrm{M}\right.$ for cyclic AMP) which is present in the cytoplasm. and it is activated by $\mathrm{Ca}^{++}$and $\mathrm{CaM}$ and hydrolyzes both cyclic AMP and cyclic GMP: and iii) the last is a high affinity form $\left(K_{m}=4\right.$ $2 \mathrm{M}$ for cyclic AMP) which is also present in the cytoplasm, but is insensitive to $\mathrm{Ca}^{++}$and $\mathrm{CaM}$ and selectively hydrolyzed cyclic AMP (15). Rolipram has been reported to inhibit only the cyclic AMP-selective phosphodiesterase $(16,17)$. Ro20-1724, which also inhibits only the cyclic AMP-selective phosphodiesterase $(16,17)$, was generalized to the $( \pm)$-rolipram stimulus. Caffeine and 

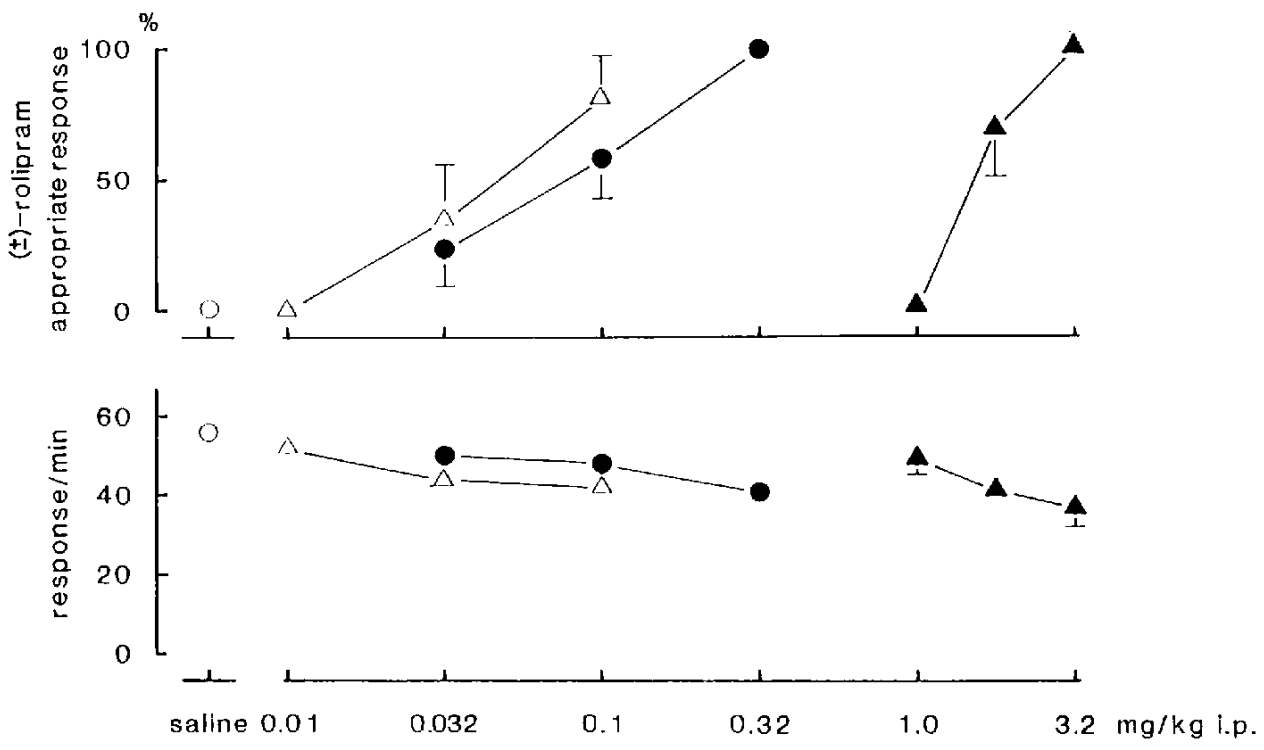

- ( $( \pm)$-rolipram $\Delta-\Delta(-)$-rolipram $\Delta(+)$-rolipram

Fig. 3. Generalization to optical isomers of rolipram by rats trained to discriminate $( \pm)$-rolipram $(0.32$ $\mathrm{mg} / \mathrm{kg}$, i.p.) from saline.
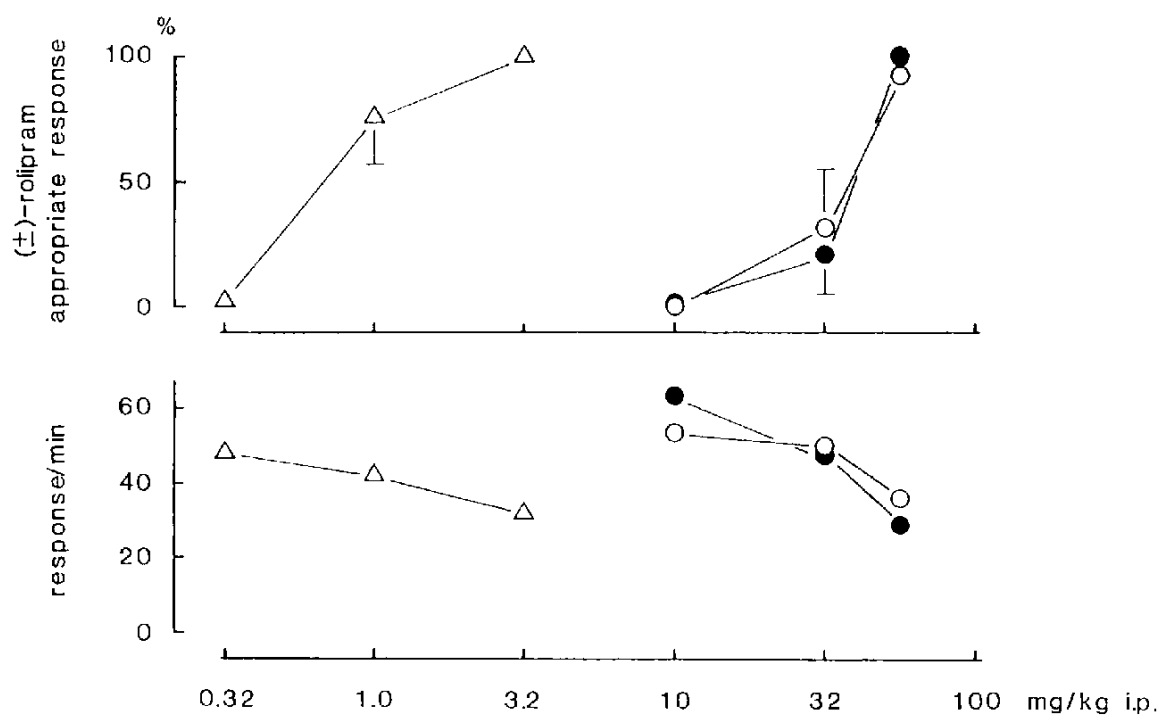

$0-0$ caffeine $\longrightarrow$ theophylline $\triangle \longrightarrow \Delta$ Ro $20-1724$

Fig. 4. Generalization to various phosphodiesterase inhibitors by rats trained to discriminate ( \pm )rolipram $(0.32 \mathrm{mg} / \mathrm{kg}$. i.p.) from saline.

theophylline differ from rolipram in that their inhibitory action shows no substrate specificity (16-18). However, both xanthines at a dose of $56 \mathrm{mg} / \mathrm{kg}$ were generalized 
almost $100 \%$ to ( \pm )-rolipram. These results suggest that the discriminative stimulus of $( \pm)$-rolipram may be related to an increase in cyclic AMP, but unrelated to the substratespecificity of phosphodiesterase inhibition.

Ro20-1724 induces hypothermia and hypoactivity similar to ( \pm )-rolipram (6, 19 . 20). Ro20-1724 is approximately 15 times less potent than $( \pm)$-rolipram in these effects. Moreover, in the present study, the required generalization dose of Ro20-1724 was about 10 times higher than the $( \pm)$ rolipram training dose. Ro20-1724 possess both reserpine-antagonistic and yohimbinepotentiating effects similar to antidepres sants $(6,7)$. Furthermore, the potent phosphodiesterase inhibitor IBMX, another xanthine derivative, also antagonizes reserpine-induced hypothermia and hypoactivity and reduces immobility time in the behavioral despair test similar to antidepressants (7). Although there are no clinical reports which have directly discussed the antidepressant effects of these phosphodiesterase inhibitors, these results suggest that phosphodiesterase inhibition may cause the antidepressant effects observed clinically $(6,7)$.

(士)-Rolipram suppressed the response rate as compared with the saline injection. It is very interesting that Ro20-1724, caffeine and theophylline reduced the response rate concurrently at the dose of generalization to $( \pm)$-rolipram, although an atypical antidepressant, mianserin, also suppressed the response rate in $( \pm)$-rolipram-trained rats. However, mianserin failed to generalize to ( \pm )-rolipram (T. Yamamoto et al., unpublished data). This finding indicates that the response rate suppression itself is not due to generalization to $( \pm)$-rolipram.

In conclusion, it was found that rats can be trained to discriminate $0.32 \mathrm{mg} / \mathrm{kg}( \pm)$ rolipram (i.p.) from saline, and that phosphodiesterase inhibition may be an important pharmacological action of $( \pm)$-rolipram in drug discrimination.

Acknowledgments: The authors are indebted to Prof. Dr. R. Counsell (University of Michigan) for his kind comments. We also wish to thank Nihon Schering for the gift of ( \pm )-rolipram and its isomers and Nihon Roche for Ro20-1724: we thank Miss
Hitomi Hitaka for typing the manuscript.

\section{References}

1 Barry, H., III: Classification of drugs according to their discriminable effects in rats. Fed. Proc. 33, 1814-1824 (1974)

2 Colpaert, F.C.: Discriminative stimulus properties of narcotic analgesic drugs. Pharmacol. Biochem. Behav. 9, 863-887 (1978)

3 Holtzman, S.G., Shannon, H.E. and Schaefer, G.J.: Discriminative properties of narcotic antagonists. In Discriminative Stimulus Properties of Drugs. Edited by Lal, H., p. 47-72, Plenum Press. New York (1977)

4 Schuster, C.R. and Balster, R.L.: The discriminative stimulus properties of drugs. In Advances in Behavioral Pharmacology, Edited by Thompson, T. and Dews, P.B., Vol. 1, p. 85-138, Academic Press. New York (1977)

5 Shearman, G., Miksic, S. and Lal, H.: Discriminative stimulus properties of desipramine. Neuropharmacology 17, 1045-1048 (1978)

6 Wachtel, H.: Patential antidepressant activity of rolipram and other selective cyclic adenosine 3'.5'-monophosphate phosphodiesterase inhibitors. Neuropharmacology 22, 267-272 (1983)

7 Przegalinski, E. and Bigajska, K.: Antidepressant properties of some phosphodiesterase inhibitors. Pol. J. Pharmacol. Pharm. 35, 233-240 (1983)

8 Horowski, R. and Sastre-Y-Hernandez, M.: Clinical effects of the neurotropic selective CAMP phosphodiesterase inhibitor rolipram in depressed patients: Global evaluation of the preliminary reports. Curr. Ther. Res. 38, 23-29 (1985)

9 Wachtel, H., Schlangen, $M$. and Seltz, A.: Potentiation of the motor stimulatory effect of the dopaminergic ergot derivative lisuride hydrogen maleate (LHM) in rats by systemic or intracerebral administration of rolipram and other adenosine-3', $5^{\prime}$-cyclic monophosphate (cAMP) phosphodiesterase (PDE) inhibitors. Progr. Neuropsychopharmacol. Supp. p. 350 (1980)

10 Schneider, H.H.: Brain CAMPresponse to phosphodiesterase inhibitors in rats killed by microwave irradiation or decapitation. Biochem. Pharmacol. 33, 1690-1693 (1984)

11 Schwabe, U., Miyake, M., Ohga, Y. and Daly, J.W: 4-(3-Cyclopentyloxy-4-methoxyphenyl)2-pyrrolidone (ZK 62711): A potent inhibitor of adenosine cyclic 3',5'-monophosphate phosphodiesterase in homogenates and tissue slice from rat brain. Mol. Pharmacol. 12, 900-910 (1976)

12 Overton, D.A. and Batta, S.K.: Relationship 
between abuse liability of drugs and their degree of discriminability in rat. In Predicting Dependence Liability of Stimulant and Depressant Drugs, Edited by Thompson, T. and Unna. K.R.. p. 125-135. University Park Press, Bartimore (1977)

13 Jones, C.N., Howard, J.L. and McBennett, S.T.: Stimulus properties of antidipressants in the rat. Psychopharmacology (Berlin) 67, 111118 (1980)

14 Wachtel, H.: Neurotropic effects of the optical isomers of the selective adenosine cyclic $3^{\prime}, 5^{\prime}-$ monophosphate phosphodisterase inhibitor rolipram in rats in-vivo. J. Pharm. Pharmacol. 35, 440-444 (1983)

15 Anderson, P.H., Klysner, R. and Geisler, A.: Cyclic AMP phosphodiesterase activity in rat brain following chronic treatment with lithium. imipramine, reserpine, and combinations of lithium with imipramine or reserpine. Acta Pharmacol. Toxicol. 53, 337-343 (1983)

16 Adachi, K. and Numano, F.: Phosphodiesterase inhibitors: their comparative effectiveness in vitro in various organs. Japan. J. Pharmacol. 27, 97-103 (1977)

17 Ruckstuhl, M. and Landry, Y.: Inhibition of lung cyclic AMP- and cyclic GMP-phosphodiesterases by flavonoids and other chromone-like compounds. Biochem. Pharmacol. 30, 697-702 (1981)

18 Anderson, P.H. and Geisler, A.: Characterization of and drug influence on a calmodulinsensitive phosphodiesterase purified from bovine brain. Acta Pharmacol. Toxicol. 53, 49-56 (1983)

19 Wachtel, $\mathrm{H}$.: Characteristic behavioral alterations in rats induced by rolipram and other selective adenosine cyclic $3^{\prime} 5^{\circ}$-monophosphate phosphodiesterase inhibitors. Psychopharmacology (Berlin) 77, 309-316 (1982)

20 Wachtel, H.: Species differences in behavioral effects of rolipram and other adenosine cyclic 3', 5'-monophosphate phosphodiesterase inhibitors. J. Neural Transm. 56, 139-152 (1983) 